\title{
Estudo do dengue em área urbana favelizada do Rio de J aneiro: considerações iniciais
}

\author{
Dengue in a Rio de J aneiro slum: \\ a preliminary analysis
}

\author{
Márcia de Freitas Lenzi 1 \\ Léa Camillo-Coura 1 \\ Carlos Eduardo Grault 1 \\ Margarida Barros do Val 1
}

\footnotetext{
1 Departamento de Ciências Biológicas, Escola Nacional de Saúde Pública, Fundação Oswal do Cruz. Rua Leopoldo Bulhões 1480, Rio de Janeiro, RJ 21040-210, Brasil. mlenzi@ensp.fiocruz.br
}

Abstract This study is part of a program to control and prevent dengue in a slum bordering on the grounds of the Oswaldo Cruz Foundation in Rio deJaneiro, Brazil. The results obtained from a questionnaireand entomological survey called attention to problems pertaining to the information transmitted by public health campaigns and its interpretation, since many practices result from misunderstanding or forgetting preventive messages. Dengue-related data include most frequent vector breeding sites, people's knowledge, and dengue-related habits. The study's conclusions in terms of dengue prevention point to the need for drafting messages not only about ideal preventive practices but also teaching possible solutions: disseminating frequent messages throughout the year and not only seasonally and planning heal th education to join health professionals and the population in the search for sustainable dengue control alternatives.

Key words Dengue; Prevention \& Control; Consumer Participation; Poverty Areas

Resumo Este estudo é parte de um programa que visa ao controle e prevenção do dengue em área urbana favelizada vizinha à Fundação Oswaldo Cruz, Rio de Janeiro, Brasil. Como resultado da aplicação de um questi onário acompanhado de levantamento entomológi co, pôde-se observar problemas ligados a informações vei culadas pel as campanhas de saúde pública para o controle do dengue, e suas interpretações por parte da população local, ao se verificar práticas que favorecem a procriação do mosquito, resultantes do esquecimento dessas mensagens ou de interpretação parcial das mesmas. Os dados provenientes do questi onário são rel ativos ao nível de informação sobre dengue, criadouros mais freqüentes; conheci mento e hábitos da população local no tocanteà endemia. As conclusões deste estudo apontam para a necessi dade de: elaboração de mensagens que informem não só práticas preventivas ideais, mas também ofereçam soluções possí veis; divulgação permanente de mensagens através da mídia; planejamento de atividades de educação em saúde para o estreitamento da relação entre profissi onais de saúde e população, com o objetivo da construção de alternativas sustentávei s para o controle do dengue. Palavras-chave Dengue; Prevenção \& Controle; Parti cipação Comunitária; Áreas de Pobreza 
Introdução

Para o controle de endemias, a saúde pública conta com ações de diversas naturezas, que visam ao impacto direto nas relações causais, e com campanhas informativas para a instrução da população quanto aos cuidados e prevenção. Porém, ao se analisar a informação nesse contexto, observa-se sua elaboração norteada pela simplificação da linguagem em detrimento da qualidade, o que compromete seus objetivos, trazendo conseqüências sociais graves. Um exemplo deste fato foi a campanha realizada pelo Governo Federal nos primeiros meses de 1998, em plena epidemia de dengue em vários estados do Brasil, que consistia na mensagem “Água limpa e parada, é dengue moçada!", acompanhada da imagem de um inseto al ado, amarelo com listras pretas, dentado, longe das reais características do mosquito transmissor, que teve como objetivo primei ro reforçar, para a população, a ameaça do mosquito e as condições favoráveis a sua procriação, provavelmente sem contribuir de modo efetivo para isso.

Exemplos como esse fazem pensar no "valor" da informação que, para o campo da saúde, está ligado à promoção de conhecimentos e hábitos preventivos de caráter educativo/integrador. A simplificação da linguagem provoca a perda de informações importantes, mantendo a população sem condições de atuar, já que al ternativas não Ihe são oferecidas e, pior, não Ihe faculta a oportunidade de desenvolver qualquer conhecimento.

Com o objetivo de incentivar a participação comunitária por intermédio da discussão de problemas coletivos, vem-se desenvolvendo um projeto de controle do dengue com participação popular em uma comunidade de baixa renda do Complexo de Favelas de Manguinhos - área vizinha ao campus da Fundação Oswaldo Cruz (FIOCRUZ), no Rio de Janeiro. A escoIha desse local foi feita em razão da existência do vetor, de registros de casos da doença no Centro de Saúde Escola Germano Sinval Faria, da Escola Nacional de Saúde Pública (ENSP)/ FIOCRUZ, e da aceitação pela comunidade da proposta de trabalho a el es apresentada, bem como pela busca de integração cada vez maior da instituição com as comunidades carentes em seu entorno.

Este trabal ho levantou dados relativos às fontes de informação utilizada no que concerne ao dengue, às práticas preventivas e às atitudes relacionadas à manutenção de criadouros para o Aedes aegypti. Buscou compreender esta última à luz dos aspectos socioculturais que as influenciam, a fim de planejar a forma de linguagem mais adequada e conteúdos para abordar problemas referidos à endemia.

\section{Metodologia}

Foi realizado um levantamento entomológico e aplicando um questionário visando obter informações que pudessem nortear a equipe técnica acerca de como o dengue era entendido pelos moradores da área.

O questionário foi aplicado em 165 domicílios, distribuídos pelas 33 ruas existentes no local (média de cinco casas por rua), durante os meses de julho e agosto de 1997, pela equipe técnica previamente treinadas. Os respondentes eram donas de casa ou pessoas responsáveis pelo domicílio.

A área é composta de 895 residências e conta com coleta de lixo feita pela Companhia Municipal de Limpeza Urbana do Rio de Janeiro (COMLURB) nas três ruas principais periféricas. Segundo os moradores, o abastecimento de água é satisfatório. Contudo, o sistema de esgotamento sanitário não sofreu qualquer redimensionamento para acompanhar o crescimento da área, dando origem a valas negras. Por sua vez, o grau de escolaridade predominante é o primeiro grau incompleto $(45,96 \%)$.

\section{Resultados e discussão}

A televisão foi apontada como fonte de informação mais freqüente a respeito do dengue, seguida pelo rádio e pela conversa informal com outras pessoas. Outras fontes de informação citadas foram (nessa ordem) escolas, jornais e a FIOCRUZ, através do seu Centro de Saúde. Não houve alusão a livros, a médicos ou a guardas sanitários da Fundação Nacional de Saúde.

A maior parte da população $(68,38 \%)$ afirmou saber como se contrai a doença, fazendo referência ao mosquito (51\%), à água ou ao ar como agente transmissor; $31,62 \%$ não conheciam ou não se lembravam da forma de transmissão. A Tabela 1 mostra as práticas preventivas mencionadas em relação ao dengue.

Para verificar os tipos de criadouros para A. aegypti existentes nessa área efetuou-se um levantamento entomológico, investigando-se o número de criadouros potenciais ou positivos por domicílio, com identificação das larvas para caracterização da espécie (Tabela 2).

Durante a primeira inspeção foram encontrados 78 criadouros positivos para os 895 domicílios ( $8 \%$ de índice de infestação). Cabe ressaltar que esse levantamento foi realizado nos 
meses de julho e agosto, meses que normalmente apresentam temperaturas e nível pluviométrico baixos, ou seja, período menos favorável para o ciclo evolutivo da espécie. Os criadouros positivos encontrados foram: pratos de planta, depósitos com planta na água, latões, garrafas, cisternas, caixas d'água, banheiras e aquários em desuso (ordem de citação relativa à proporção numérica).

Comparando-se os dados das duas tabelas, pode-se atentar que várias práticas preventivas mencionadas não condiziam com as reais atitudes, levantando al gumas consi derações quanto ao nível de conhecimento no que tange à transmissão e prevenção e ao desenvolvimento de um tipo de comportamento necessário à diminuição dos riscos relativos ao dengue. As mensagens educativas exercem papel importante neste aspecto, já que o acesso a informações de qualidade ajudam na promoção de comportamentos preventivos.

O problema de assimilação e compreensão das informações relativas ao dengue pode estar baseado no caráter não permanente de divulgação e na forma pela qual elas são elaboradas e passadas à população - fragmentadas, incompletas e, de modo predominante, por meios de comunicação de massa que impossibilitam a discussão e a possibilidade de eliminação de dúvidas, gerando assim uma compreensão parcial do problema e miscelânea de interpretações. Entretanto, a televisão e o rádio, em virtude de serem bens aos quais a maioria da população tem acesso, poderiam ter papel relevante nas campanhas de saúde, pela possibilidade de promover programas de caráter interativo, divulgando permanentemente informações mais completas e criando um espaço de discussão entre os ouvintes.

Além da falta de reiteração das propagandas e do reducionismo de seus significados, verifica-se também a falta de trabalho esclarecedor por parte dos guardas sanitários - não capacitados para essa tarefa - e a pouca participação do sistema de ensino junto às crianças e jovens no tocante à promoção de práticas preventivas e promocionais de saúde, que poderiam proporcionar oportunidades tanto para discussão do assunto quanto para dirimir dúvidas, as quais ficam, muitas vezes, sem resposta.

Pode-se notar que, em função da compreensão parcial da doença, a população observada desenvolve práticas que em nada favorecem o combate ao mosquito do dengue - de hábito diurno -, como, por exemplo, usar inseticidas e ventiladores - práticas noturnas.

A manutenção do quintal limpo, muito citada como prática preventiva, mostra clara-
Tabela 1

Práticas preventivas mencionadas.

\begin{tabular}{lcc}
\hline Modo de prevenção* & Freqüência na amostra & $\%$ \\
\hline Manter caixa d'água fechada & 328 & 36,65 \\
Manter o quintal limpo & 271 & 30,28 \\
Trocar água das plantas & 226 & 25,25 \\
Não armazenar água & 148 & 16,54 \\
Não faz nada & 113 & 12,63 \\
Cobrir garrafas vazias & 107 & 11,96 \\
Usar inseticidas & 52 & 5,81 \\
Outros** & 227 & 25,36 \\
\hline
\end{tabular}

* Os percentuais são relativos ao total de domicílios (895).

** O utros - em ordem decrescente de freqüência: não ter depósitos com plantas em água; manter a casa limpa; ferver ou filtrar a água; usar inseticida; colocar cloro ou desinfetante na água e nos ralos; tomar injeção; usar ventilador.

Tabela 2

Tipos de criadouros encontrados.

\begin{tabular}{lcc}
\hline Tipos de criadouros & Freqüência na amostra & $\%$ \\
\hline Pratos de planta & 187 & 20,89 \\
Depósitos com plantas na água & 176 & 19,66 \\
Caixas d'água mal tampadas & 123 & 13,74 \\
Recipientes pequenos nos quintais & 75 & 8,38 \\
Latões & 73 & 8,16 \\
Garrafas & 53 & 5,92 \\
Pneus & 10 & 1,12 \\
Calhas & 08 & 0,89 \\
Cisternas mal tampadas & 06 & 0,67 \\
\hline
\end{tabular}

mente um problema de representação, pois os reservatórios encontrados nos quintais - tais como vasilhames pequenos, pneus, latões, entre outros - são considerados, pelos moradores, como "coisas de serventia" (sic) e não "Iixo". Neste sentido, existe a necessidade de se entender essas representações e de trabalhar, junto à população, formas seguras de guardar esse tipo de material, em lugar de limitar-se à aplicação do larvicida e insistir em sua eliminação.

Em relação aos criadouros existentes nessa localidade, o prato para suporte de plantas foi o mais freqüente em número e positividade; entretanto, é pouco enfatizado pelas campanhas. Este fato talvez aponte para a necessidade de estudo atualizado acerca dos tipos de criadouros para dengue no Rio de Janeiro, de modo a formular novas estratégias de campanhas. 
A manutenção de depósitos com plantas na água exemplifica como as campanhas de combate ao dengue vêm sendo insuficientes. Tendo como base um estudo feito em 1984/ 85 por Moura Lima, Aragão \& Amaral (M oura-Lima et al., 1988) a respeito dos tipos de criadouros de A. aegypti em alguns bairros do Rio de Janeiro, pode-se atentar no crescimento desse hábito, ao contrário do que se esperava na época como possível resultado das campanhas. Naquele período, o criadouro predominava em "casas de classe média de bom padrão" e sua introdução veio mudar a situação dos focos de A. aegypti no Rio de Janeiro. Porém foi sugerido pelos autores que "em virtude desse hábito ser recente, deve ser fácil de ser eliminado. Uma campanha pela tel evisão, como a que vem sendo feita permanentemente em Cuba depois da epidemia de dengue em 1981, talvez el imi nasse esse hábi to de manter recipientes com água e plantas vivas" (Moura-Lima et al., 1988:298).

Outro problema detectado nessa área foi em relação às caixas d'água. Em favelas urbanas é comum que esse tipo de reservatório esteja mal tampado ou com tampa danificada, em virtude de um dado cultural usual entre as crianças: soltar pipa nas lajes, já que a construção compacta das casas não permite que utilizem as ruas por falta de espaço. Uma vez quebradas, a substituição das tampas tornase difícil pelo custo que isto implica, não havendo divulgação de al ternativas para tal problema.

Além da informação relativa às formas de contágio e prevenção, procurou-se investigar se o contato direto ou indireto com a doença influenciaria a existência de criadouros no domicílio. Para isso, levantou-se o número de casos mencionados de dengue no período de 1986 a 1997, associando-o com a existência ou não de criadouros. A equipe considerou os casos mencionados pelos entrevistados, que eram pessoas responsáveis pela casa e família (Tabelas 3 e 4).

Tabela 3

Número de casos de dengue mencionados por domicílio

\begin{tabular}{lcc}
\hline Resposta & Freqüência estimada & $\%$ \\
\hline Teve dengue & 381 & 42,57 \\
Não teve & 490 & 54,75 \\
Não sabe & 24 & 2,68 \\
Total & 895 & 100 \\
\hline
\end{tabular}

Observa-se que, mesmo existindo contato direto ou indireto com a doença - que apresenta, em geral, sintomas desconfortáveis -, o procedimento em relação à manutenção de criadouros intradomiciliares não chega a ser alterado. No entanto, a mudança de comportamento é fundamental para o combate ao dengue e outras endemias e é questão que vem sendo refletida com seriedade atualmente, já que o nível de conhecimento de uma população não acarreta necessariamente alterações nas práticas. Vale apontar que em alguns trabalhos já realizados, em que se atribuía forte ênfase ao caráter educativo e ao envolvimento da população, a mudança comportamental não foi alcançada no grau desejado para modificar de forma significativa o parâmetro de transmissão do dengue (Gubler \& Clark, 1994; Rosenbaum et al., 1995; Chiavaralloti Neto et al., 1998).

A rede de tratamento procurada pelo doente também foi investigada, e verificou-se que, dentre as 381 pessoas que mencionaram ter contraído dengue, 308 foram ao médico (81\%). As demais não procuraram auxílio profissional sob a al egação de que já sabiam o que fazer ou porque estavam sem condições físicas para se deslocarem até o lugar de atendimento. Os locais mais procurados pelos moradores da localidade para tratamento de saúde são apresentados na Tabela 5.

O Posto de Saúde da ENSP/FIOCRUZ constitui espaço importante para esclarecimento da população local a respeito do dengue e demais problemas de saúde em virtude de ser o local de atendimento da maioria da população da área entrevistada, desenvolvendo uma relação entre usuários e serviço que deve ser cada vez mais estimulada pelas campanhas e pelos próprios profissionais de saúde.

\section{Considerações finais}

A despeito de as novas tecnologias surgidas, incluindo as comunicacionais, contribuírem para a qualidade de vida do homem, o acesso a elas ainda é restrito, enfrentando-se hoje a manutenção de uma sociedade em que o crescimento econômico, as melhorias estruturais das cidades e o acesso à educação, que colaboram para melhorar o nível de saúde, são partilhados por poucos, enquanto muitos continuam sem emprego, habitação, hospitais próximos, transporte, escolas e outros serviços básicos. Notase claramente a existência de sociedades paralelas, como descrito por Martin-Barbero (1999): "Ia de los conectados a infinita oferta de bienes y saberes y la de los excluidos cada vez más 
Tabela 4

Relação dos casos de dengue e manutenção de criadouros para Aedes aegypti.

\begin{tabular}{|c|c|c|c|c|}
\hline \multirow{2}{*}{$\begin{array}{l}\text { A casa tem criadouro } \\
\text { para A. aegypti? }\end{array}$} & \multicolumn{4}{|c|}{ Alguém na sua casa já teve dengue? } \\
\hline & $\operatorname{Sim}(\%)$ & Não (\%) & Não Sabe (\%) & Total \\
\hline Sim & $248(27,71)$ & $240(26,82)$ & $6(0,67)$ & 494 \\
\hline Não & $119(13,30)$ & $225(25,14)$ & $18(2,01)$ & 362 \\
\hline Ignorado* & $14(1,56)$ & $25(2,79)$ & 0 & 39 \\
\hline Total & 381 & 490 & 24 & 895 \\
\hline
\end{tabular}

* Casas cujos moradores não autorizaram o levantamento entomológico.

abiertamente tanto de los bienes como de la capacidad de decidir".

A compreensão de como essa comunidade se comporta em relação ao dengue é de extrema importância para um projeto mais amplo de controle participativo, pois tal comportamento advém do grau de compreensão e de interpretação das informações atinentes à doença relacionadas à organização sociocultural de um grupo. As propagandas difundidas pelas campanhas de saúde pública pouco interferem no cotidiano das pessoas entrevistadas, e alguns fatores podem ser diretamente responsáveis pela falta de impacto dessas mensagens, tais como a sua forma de elaboração, a ausência de contato direto entre população e técnicos capacitados que possam buscar juntos soluções efetivas para o combate à endemia, os problemas sócio-econômicos que afligem, em especial, a classe menos favorecida, descrédito no governo e, em conseqüência, o desinteresse.

Um estudo aprofundado no que concerne às alternativas educacionais e comunicacio-
Tabela 5

Rede de tratamento utilizada.

\begin{tabular}{lcc}
\hline Local & Freqüência estimada & $\%$ \\
\hline CSEGSF/EN SP/FIO CRUZ & 557 & 62,23 \\
Consultório Particular & 142 & 15,87 \\
PAM Del Castilho & 91 & 10,17 \\
Hospital Geral de Bonsucesso & 50 & 5,58 \\
Outros & 55 & 6,15 \\
Total & 895 & 100 \\
\hline
\end{tabular}

CSEGSF = Centro de Saúde Escola Germano Sinval Faria;

ENSP = Escola Nacional de Saúde Pública; FIO CRUZ = Fundação O swaldo Cruz; PAM = Posto de Atendimento Médico.

nais poderá subsidiar a construção de programas mais abrangentes que tomem em conta os fatores comportamentais de risco como reflexos sócio-econômicos e culturais, propondo ações coletivas e envolvendo a população na busca de novas estratégias apropriadas às condições materiais e sociais em que vivem.

\section{Agradecimentos}

Projeto financiado pelo Programa de Apoio a Pesquisas Estratégicas em Saúde (PAPES) da Fundação Oswaldo Cruz . 


\section{Referências}

CHIAVARALLOTI NETO, F. C.; MORAES, M. S. \& FERNANDES, M. A., 1998. Avaliação dos resultados de atividades de incentivo à participação da comunidade no controle da dengue em um bairro periférico do Município de São José do Rio Preto, São Paulo, e da relação entre conhecimentos e práticas desta população. Cadernos de Saúde Pública, 14:91-100.

GUBLER, D. J. \& CLARK, G. G., 1994. Communitybased integrated control of Aedes aegypti: A brief overview of current programs. American Journal of Tropical Medicineand Hygiene, 50:50-60.

MARTIN-BARBERO, J., 1999. Comunicación fin de siglo - Para dónde va nuestra investigación. 1999 বttp:// www.innovarium.com/investigacion/co mjmb.htm>.
MOURA-LIMA, M.; ARAGÃO, M. B. \& AM ARAL, R. S., 1988. Criadouros de Aedes aegypti encontrados em alguns bairros do Rio de Janeiro, 1984-85. Cadernos de Saúde Pública, 4:293-300.

ROSENBAUM, J.; NATHAN, M. B.; RAGOONANAN SIRGH, R.; RAWLINS, S.; GAYLE, C.; CHADEE, D. D. \& LLOYD, L. S., 1995. Community participation in dengue prevention and control: A survey of knowledge, attitudes and practice in Trinidad and Tobago. American Journal of Tropical Medicine and Hygiene, 53:111-117. 